\title{
Percent Recovered Infinity Predicted Normalized by Surface Area
}

National Cancer Institute

\section{Source}

National Cancer Institute. Percent Recovered Infinity Predicted Normalized by Surface

Area. NCI Thesaurus. Code C112393.

The percentage of the recovered administered dose extrapolated to infinity, calculated using the predicted value of the last non-zero concentration, divided by the surface area. 